\title{
A Comparative Investigation of the Interpretation of Colour Terms in the Quran
}

\author{
AMAL ABDELSATTAR METWALLY ${ }^{1}$
}

\begin{abstract}
The present study attempts to focus on the interpretation of colour terms in the EverGlorious Quran. The study examines whether it is possible to observe any consistency in the strategies used for the interpretation of colour-terms in the Ever-Glorious Quran. The validity of the notion of foreignisation as brought to the fore of translation studies and advocated by Venuti (1995) is explored. Paraphrase as a strategy adopted by some interpreters of the Ever-Glorious Quran is also investigated. The study, moreover, explores the idiomacity of some colour terms in the Ever-Glorious Quran, and investigates the strategies employed in interpreting such idiomatic expressions. This is attempted under the foreignisation strategy proposed by Venuti (1995) and the framework of Berlin with Kay studies on colours (1969). The present study is a comparative analysis of three authentic interpretations of the Ever-Glorious Quran, namely Pickthall (1938), M. Asad (1980) and Yusuf Ali (1992). The paper describes already-existing interpretations in order to make generalization about translation methods.
\end{abstract}

Keywords: colour term, foreignisation, paraphrase, Quran translation, the Quran

The Holy Quran was revealed in the Arabic language, and any translation, at best, is an attempt to offer an interpretation of the message. Some interpreters are more faithful to the original as if they are providing literal translation and in doing this, they are following the foreignisation strategy, while others are loose with their interpretations of the meaning into English and in that they are following the paraphrase approach.

In the Holy Quran, six basic colour terms are present; white, black, red, green, yellow and blue. In addition to their descriptive sense, some colour words, such as black, white and blue, are also used metaphorically to suggest a psychological or emotional state of being. In addition to these basic colour terms, there are also eight references to the word 'colour' (lawn), most often collocated with the adjective (mukhtalif) (i.e. diverse) i.e. 'diverse colours' (mukhtalif alwanuh) (al-Nahl 16: 69). The use of this adjective, especially in connection with multicoloured natural entities such as mountain rocks, fruits, plants and animals, suggests that the range of the red, green and yellow is likely to be much wider than the assumed norm. Red, for example, will probably include not just the most typical example of the colour represented by the term but all the dark reds, browns, oranges and purple.

${ }^{1}$ Amal Abdelsattar Metwally, Ph.D., lecturer at Faculty of Languages and Translation, King Khalid University, ABHA, Saudi Arabia, email: amalmetwally8@gmail.com. 


\section{Review of Literature}

This review of literature explores the notion of foreignisation and its application to the interpretation of colour terms in the Ever-Glorious Quran. "Paraphrase" is explored as well to verify that it is a powerful strategy to be adopted in handling the idiomacity indicated by some colour-terms.

Colours have received much attention in linguistics because of their apparently universal character. All humans with normal vision can see colours and names are given in order to make reference to them. But not all cultures name all colours, and colours realization differs from language to language, culture to culture (Philip 2006). As such, despite recent developments in the field of translation theory, idiomatic expressions still cause problems that relate to two main areas: recognising and interpreting them properly and rendering the 'intended' meaning into the target language (Baker 1992: 68).

Most significantly, many studies have been carried out on colour-terms in the Ever-Glorious Quran. Metwally (2019) examines the strategies for translating Arabic colour-related expressions. Al-Bzour (2015) investigates the connotations of the straightforward colours in the Ever-Glorious Quran in which he emphasizes the importance of the colours depending on their moral lessons. AlDomi (2015) explores the connection between the colours mentioned in the Ever-Glorious Quran and their significance focusing on the green model. Al-Shawi (2014) explores the significance of colours in the Ever-Glorious Quran and the ethics of translating them into English. Al-Adaileh (2012) examines the connotations of Arabic colour terms where he explores the significant uses of some colours in Arabic language.

Colour-Related Idioms: Because of its thorough scope, Berlin and Kay's (1969) survey of colour terms provides a platform for most linguistic and translation research involving colours. The aim of studying them is to identify the basic colour terms for each of the languages studied, and the order in which these come into use, with a view to identify a mechanism towards the acquisition of colour terms in languages as a whole (Berlin \& Kay 1969: 5ff).

Foreignisation versus Paraphrase: One of the main notions on which the present study is based is Venuti's notion of the translator's invisibility. The terms 'foreignisation' and 'domestication' have been coined by Venuti (1995) as a means of providing a classification of translation strategies. Venuti (1995: 240) indicates that translation strategies "involve the basic tasks of choosing the foreign text to be translated and developing a method to translate it". He employs the concepts of domesticating and foreignising to refer to translation strategies (1998: 67). To Venuti, domestication, or translator invisibility, consists in translating in a clear and intelligible way which erases the foreignness of the source text in order to meet the needs and values of the target culture (Ramiere 2006). Similarly, paraphrase, as a domestication-biased technique tends to restate the meaning in a clearer form in order to smoothly transfer the embedded message from the source language (SL) to the target language (TL). By adopting 'paraphrase', a translator is free from abiding by the grammatical structures of the (SL). As such, a translator can produce more accurate renderings owing to the freedom given to him or her from being committed to certain idiomatic structures.

\section{Methodology}

The study relies on Venuti's (1995) foreignisation (SL-oriented translation) versus employing paraphrase towards interpreting colour terms in the Ever-Glorious Quran. The former is a parallel word-for-word translation that aims at rendering the form of the (SL) into the (TL). "Paraphrase" is a 'facilitated' translation that aims at conveying the meaning of the (SL) rather than the form (Metwally 2019). To address the gap in the literature (i.e. the interpretation of colour terms in the 
Vol. 16: (Dec.) 2019

Ever-Glorious Quran), the present paper employs foreignisation (Venuti, 1995) and paraphrase as a TL-biased technique.

\section{Foreignisation (SL-Oriented Translation)}

The term foreignisation (SL-oriented translation) can be translated into' التغريب أو إضفاء الطابع الأجنبي'. This strategy, which translates an idiom by the nearest equivalent idiom in the target language, works in two modes: a mode in which there happens to be a (TL) replica of a (SL) idiom and a mode in which the (SL) idiom is translated literally without being unintelligible. The effect of this strategy, when applicable, is to preserve the impact of the (SL) idiom since the translation maintains the lexical constituents, the semantic content and most importantly the effect of the source text (Abu-Ssaydeh 2004; Metwally 2019).

\section{Paraphrase}

The second mode of interpretation investigated in this study is 'paraphrase'. Paraphrase is defined by Baker (1992: 71-78) as "expressing the meaning of an item in other words because no match can be found in the (TL) or because of differences in stylistic preferences of the (SL) and (TL)". This is by far the most common way of translating idioms when a match cannot be found in the target language or when it seems inappropriate to use idiomatic language in the target text because of differences in stylistic preferences of the source and the target languages (Baker 1992: 74-75). Among the advantages of this method is producing more accurate renderings due to the freedom allowed to the translator from being committed to idiomatic structures. Thus, whenever the two cultures and the languages in question are very different, paraphrasing tends to be the most acceptable strategy (AbuSsaydeh 2004: 6).

\section{Interpretation of Colour Terms in the Quran}

In this study, the interpretations of some of the verses including colour-terms in the Ever-Glorious Quran are discussed with an elaborate analysis of each interpretation. Three of the most well-known authentic interpretations of the Ever-Glorious Quran are introduced; namely the interpretations of Pickthall (1938), Muhammad Asad (1980) and Yusuf Ali (1992). This section is an analysis of the three authentic interpretations to reach a conclusion regarding the translation strategies applied when translating colour-terms in the Ever-Glorious Quran. For example, the colour 'white' and its different indications is explored (Ali 'Imran 3:107):

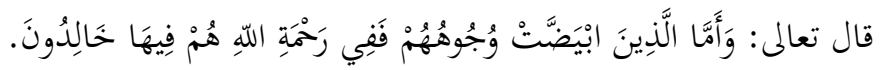

The colour 'white' here denotes happiness and bliss as those who are going to be in Allah's mercy are not necessarily of white complexion. Two of the three interpretations investigated in this study show that the foreignisation strategy is employed in translating the colour term 'white' in this verse.

Pickthall: And as for those whose faces have been whitened, in the mercy of Allah they dwell forever. 
Yusuf Ali: But those whose faces will be (lit with) white, they will be in (the light of) Allah's mercy: therein to dwell (forever).

However, in Asad's interpretation, the paraphrase strategy is followed as he did not use the colour term 'white' and instead he suggested the adjective 'shining' to indicate the content of the believers expressed on their 'shining' faces.

Muhammad Asad: But as for those with faces shining, they shall be within God's grace, therein to abide.

There is in the Ever-Glorious Quran, also, repetitive references (five occurrences) to Moses' 'white hand' (Taha 20:22) which, along with his staff, is described as a miraculous sign of God's power.

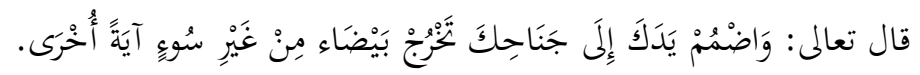

Again, one interpretation of the colour 'white' in this verse adopts the foreignisation strategy in that it retains the same colour term:

Pickthall: And thrust thy hand within thine armpit, it will come forth white without hurt. (That will be) another token.

On the other hand, in the following two interpretations, the paraphrase 'shining' is provided in addition to the colour term.

Yusuf Ali: Now draw thy hand close to thy side: It shall come forth white (and shining), without harm (or stain), as another Sign.

Muhammad Asad: Now place thy hand within thy armpit: it will come forth [shining] white, without blemish, as another sign [of Our grace].

Equally interesting is the expression 'white wine' served as a reward for the faithful in the Paradise (al-Saffat 37:45-46):

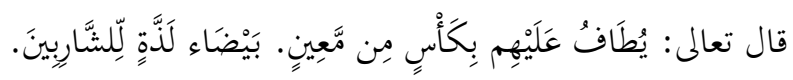

In the interpretation of this verse, the colour term white is provided in the interpretation of Pickthall, modified by the adjective crystal in Yusuf Ali's and not referred to at all in Asad's interpretation. Hence, the first two interpretations are following the foreignisation strategy while that of Asad is a paraphrase of the meaning.

Pickthall: A cup from a gushing spring is brought round for them, White, delicious to the drinkers,

Yusuf Ali: Round will be passed to them a Cup from a clear-flowing fountain, Crystalwhite, of a taste delicious to those who drink (thereof), 
Muhammad Asad: A cup will be passed round among them [with a drink] from unsullied springs, clear, delightful to those who drink it.

In his interpretation, Asad used the adjective 'clear' to indicate the purity and the whiteness of the drink. So, his interpretation is a paraphrase of the meaning intended. The colour 'white' also indicates blindness in Arabic. Hence the reference in (Yusuf 12:84) to Jacob's eyes turning white in grief over the loss of his son Joseph:

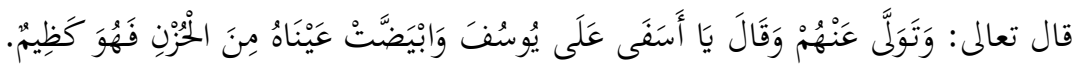

In the interpretation of the expression (wabyaddat 'aynah), the English colour term is employed in two interpretations. Hence, the foreignisation strategy is applied. However, it is paraphrased in Asad's interpretation where he used the expression "became dim" to indicate the meaning of 'losing eyesight'.

Pickthall: And he turned away from them and said: Alas, my grief for Joseph! And his eyes were whitened with the sorrow that he was suppressing.

Yusuf Ali: And he turned away from them and said: "How great is my grief for Joseph!" And his eyes became white with sorrow, and he fell into silent melancholy.

Muhammad Asad: But he turned away from them and said: "O woe is me for Joseph!"and his eyes became dim from the grief with which he was filled.

Black, on the contrary, is employed most of the times to denote sadness and depression. It tends to anchor in gloom and grief as it is clear in the following verse (al-Zumar 39:60):

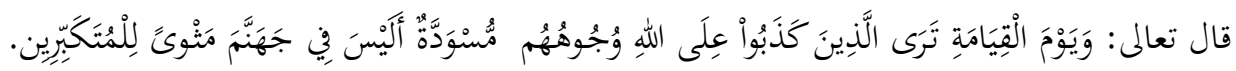

In two interpretations, foreignisation is employed and the colour term black is used to indicate the feeling of deep sadness.

Pickthall: And on the Day of Resurrection thou (Muhammad) seest those who lied concerning Allah with their faces blackened. Is not the home of the scorners in hell?

Yusuf Ali: On the Day of Judgment wilt thou see those who told lies against Allah- their faces will be turned black; Is there not in Hell an abode for the Haughty?

However, Asad tends to paraphrase the colour black in the expression 'wujuhuhum muswadda' by using the expression "their faces darkened (by grief and ignominy)".

Muhammad Asad: And [so,] on the Day of Resurrection thou wilt see all who invented lies about God [with] their faces darkened [by grief and ignominy]. Is not hell the [proper] abode for all who are given to false pride? 
Another context in which the colour black is used is that of anger and dissatisfaction. As it is clear from the following verse (al-Nahl 16:58):

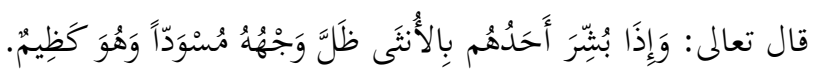

In the interpretation of the expression 'wajhuhu muswadda', the three interpretations followed the paraphrase strategy by using the expressions 'darkened' in one interpretation and 'darkens' in the other two interpretations.

Pickthall: When if one of them receiveth tidings of the birth of a female, his face remaineth darkened, and he is wroth inwardly.

Yusuf Ali: When news is brought to one of them, of (the birth of) a female (child), his face darkens, and he is filled with inward grief!

Muhammad Asad: for, whenever any of them is given the glad tiding of [the birth of] a girl, his face darkens, and he is filled with suppressed anger.

It is important to note that black and white occur separately and together most often in the same context of bliss and gloom. Psychologically, the colour white indicates bliss and happiness evident on the 'faces' of the believers in Paradise, as opposed to black which indicates gloom and dismay on the 'faces' of disbelievers in Hell. Furthermore, one of the most significant colourcombinations in the Ever-Glorious Quran is the white-black pattern found in (al-Baqarah 2:186).

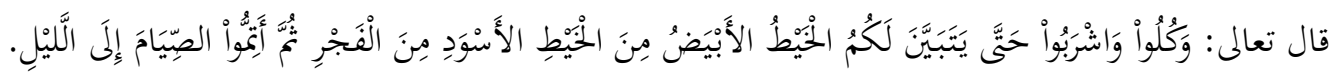

In the early days of Islam, the Muslims held to a strict rule of fasting from the evening meal of one day until the evening meal of the next. By the revelation of this verse, the present practice of fasting from first light -as defined by the ability to tell between a white and black thread- until sundown was established. This combination is significant since it refers to the physical properties of the two colours (i.e. the white thread and the black thread separating daybreak and night). In two of the three interpretations on discussion, the definite colour terms black and white are used.

Pickthall: and eat and drink until the white thread becometh distinct to you from the black thread of the dawn. Then strictly observe the fast till nightfall.

Yusuf Ali: and eat and drink, until the white thread of dawn appears to you distinct from its black thread; then complete your fast till the night appears.

In the above interpretations the colour terms are maintained and hence the foreignisation strategy is used. However, Asad prefers to contrast the white streak of dawn with 'the darkness of night' to indicate the intense darkness of night. Hence, he is following the paraphrase strategy.

Muhammad Asad: And eat and drink until you can discern the white streak of dawn against the blackness of night, and then resume fasting until nightfall. 
Another combination of colours in the Ever-Glorious Quran is the triadic combination of white, red and black in Fatir 35:27:

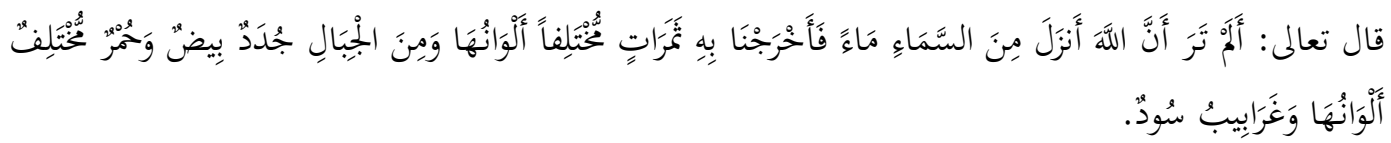

In the interpretation of the colour terms in this verse, all translators tend to use the same colour terms. But, in the interpretation of 'mukhtalifa alwanuha' they give different interpretations adopting the paraphrase strategy: 'of different colours, of diverse hues, of various colours, of various shades of colour, of many hues and of various shades'.

Pickthall: Hast thou not seen that Allah causeth water to fall from the sky, and We produce therewith fruit of diverse hues; and among the hills are streaks white and red, of diverse hues, and (others) raven-black;

Yusuf Ali: Seest thou not that Allah sends down rain from the sky? With it We then bring out produce of various colours. And in the mountains are tracts white and red, of various shades of colour, and black intense in hue.

Muhammad Asad: ART THOU NOT aware that God sends down water from the skies, whereby We bring forth fruits of many hues - just as in the mountains there are streaks of white and red of various shades, as well as (others) raven-black,

This verse, like many other verses in the Ever-Glorious Quran, shed light upon very significant facts concerning colours and their categorisation. The lexical item 'bayd' (i.e. white in plural) is evidence of the countless degrees of whiteness and of how perfectly aware of different degrees of a colour the Arabs were. Similarly, 'humr', the word 'red' in plural is to show that there is not just one colour red, but there are many shades and degrees of it. As for the colour blue, it occurs just once in the Ever-Glorious Quran to describe those who will not be included in Allah's mercy in the Day of Judgment. In fact, the expression 'zurqa' in (Taha 20:102) has been a subject of much debate.

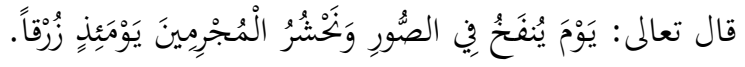

According to al-Qurtubi (1964), the blue colour here refers to the utmost 'thirst' of the criminals which thereby makes their bodies turn blue. All colours have a psychological indication and these indications are the same in different languages. In the case of 'zurqan', the criminals may be visibly blue in colour and this is symptomatic of their physical predicament. What seems to support a psychological reading of the colour is the fact that the adjacent verses concentrate on the extreme fear, confusion and terror of the 'criminals' as they wait for the judgment of God. However, the specific reference to the colour blue is not followed in the other interpretations. Pickthall, for example, translates the term 'zurqan' into 'white-eyed (with terror)', preferring to negate the 'blue', and even translating it in terms of its near opposite 'white' while emphasizing the psychological indication of the term in parenthesis (with terror).

Pickthall: The day when the Trumpet is blown. On that day we assemble the guilty whiteeyed (with terror). 
Pickthall is following the paraphrase strategy in his interpretation of the colour expression 'zurqan'. On the other hand, Yusuf Ali translates the term as 'blear-eyed (with terror)', adding in a footnote that it denotes eyes afflicted with dimness and blindness and hence metaphorically bleary or tearful with terror.

Yusuf Ali: The Day when the Trumpet will be sounded: that Day, We shall gather the sinful, blear-eyed (with terror).

In his interpretation, Yusuf Ali is using the paraphrase strategy. Similarly, Asad prefers to provide a paraphrase of the expression 'zurqan' as he rendered it into 'their eyes dimmed (by terror)':

Muhammad Asad: On the Day when the trumpet is blown: for on that Day We will assemble all such as had been lost in sin, their eyes dimmed [by terror].

Regarding the colour term red, it occurs once in the Holy Quran in the plural form 'humr' in the aforementioned verse (Fatir 35:27). However, it is significant to note that the colour red is also inherent in the word 'wardah' (al-Rahman 55:37), which means 'red rose'. In fact, scholars have noted, in recent times, the interesting scientific fact that when small stars erupt in space they turn into a rose-like greasy shape:

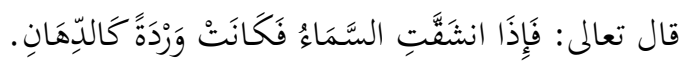

In the interpretation of the word 'wardah', the adjective rosy is used in one of the three interpretations under discussion and the colour term red is used in the other two. As such, foreignisation strategy is followed in the first interpretation while paraphrase is followed in the other two. Pickthall indicated the red colour of sky in his interpretation 'rosy like red hide', and in doing that he follows the paraphrase strategy.

Pickthall: And when the heaven splitteth asunder and becometh rosy like red hide.

However, Dr. Yusuf Ali uses the colour 'red' instead.

Yusuf Ali: When the sky is rent asunder, and it becomes red like ointment.

On the other hand, Asad prefers in his interpretation to provide the adjective 'burning' to describe the intensity of the red colour; and in doing so he is following the paraphrase strategy.

Muhammad Asad: And when the sky is rent asunder and becomes red like [burning] oil.

The colour yellow appears five times in the Ever-Glorious Quran. It is repeatedly used to denote the withering process of plants, with an explicit reference to the fact that plants of all colours must by necessity turn to yellow as in al-Hadid 57:20: 


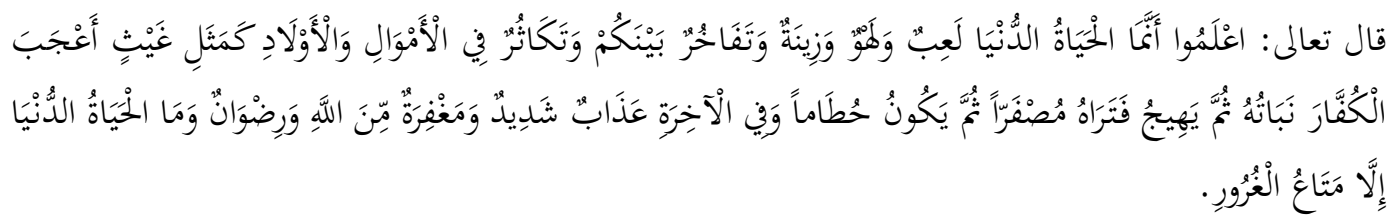

Pickthall: Know that the life of the world is only play, and idle talk, and pageantry, and boasting among you, and rivalry in respect of wealth and children; as the likeness of vegetation after rain, whereof the growth is pleasing to the husbandman, but afterward it drieth up and thou seest it turning yellow, then it becometh straw. And in the Hereafter there is grievous punishment, and (also) forgiveness from Allah and His good pleasure, whereas the life of the world is but matter of illusion.

Yusuf Ali: Knowye (all), that the life of this world is but play and amusement, pomp and mutual boasting and multiplying, (in rivalry) among yourselves, riches and children. Here is a similitude: How rain and the growth which it brings forth, delight (the hearts of) the tillers; soon it withers; thou wilt see it grow yellow; then it becomes dry and crumbles away. But in the Hereafter is a Penalty severe (for the devotees of wrong). And Forgiveness from Allah and (His) Good Pleasure (for the devotees of Allah.. And what is the life of this world, but goods and chattels of deception?

Muhammad Asad: KNOW [O men] that the life of this world is but a play and a passing delight, and a beautiful show, and [the cause of] your boastful vying with one another, and [of your] greed for more and more riches and children. Its parable is that of [lifegiving] rain: the herbage which it causes to grow delights the tillers of the soil; but then it withers, and thou canst see it turn yellow; and in the end it crumbles into dust. But [the abiding truth of man's condition will become fully apparent] in the life to come: [either] suffering severe, or God's forgiveness and His goodly acceptance: for the life of this world is nothing but an enjoyment of self-delusion.

All the interpretations of the colour yellow in this verse are foreignised. The exact colour term is used by all interpreters to describe the withering and decay of plants. However, in addition to death and decay, yellow is also used to denote more positive senses of brightness and beauty. This is evident in a famous and oft-quoted passage (al-Baqarah 2:69), referring to the heifer of 'bright yellow colour' (safra lawnuha) that Moses had ordered the Israelites to slay in expiation of a murder:

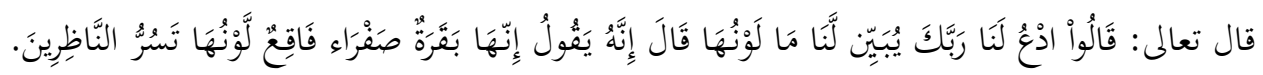

The use of the adjective 'bright' (faqi' lawnuha) not only heightens the colour in terms of luminosity and saturation, but also succeeds in stripping away the element of negativity attached to the term. This is further emphasized by using the expression, 'pleasing to the beholders' (tasurr alnadhirin). Pickthall and Asad adopted the foreignisation strategy and used the exact colour term with no further paraphrase:

Pickthall: They said: Pray for us unto thy Lord that He make clear to us of what colour she is. (Moses) answered: Lo! He saith: Verily she is a yellow cow. Bright is her colour, gladdening beholders. 
Muhammad Asad: Said they: "Pray on our behalf unto thy Sustainer that He make clear to us what her colour should be."[Moses] answered: "Behold; He says it is to be a yellow cow, bright of hue, pleasing to the beholder."

However, Yusuf Ali tended to use the compound adjective 'fawn-coloured' to indicate the pale yellowish-brown colour of the cow and uses the two adjectives 'pure and rich' to refer to the brightness of the colour. So, it appears that he adopts the paraphrase strategy in this interpretation:

Yusuf Ali: They said: "Beseech on our behalf Thy Lord to make plain to us Her colour." He said: "He says: A fawn-coloured heifer, pure and rich in tone, the admiration of beholders!"

The colour green (khudra) (al-Kahf 18:31) ranks high in terms of frequency of occurrence; it is in fact the second in number of occurrences after white. Semantically, these two colours seem to share one aspect, namely that they seem to be the primary colours of Paradise. The dwellers of heaven are not only repetitively described as having 'white' faces full of comfort and peace but also as being adorned in 'green'.

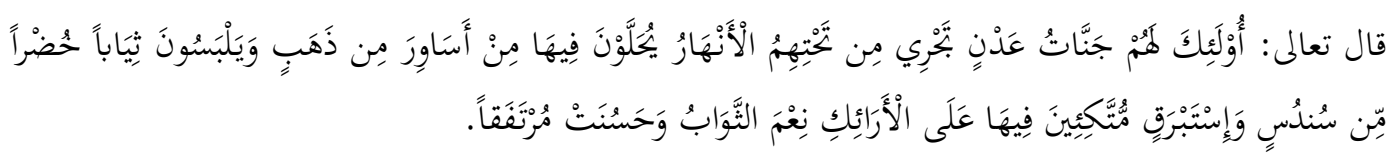

As for the interpretation of 'thiyaba khudra' in this verse, all of the three interpretations investigated on this paper adopt the foreignisation strategy in translating it into green clothes, garments or robes.

Yusuf Ali: For them will be Gardens of Eternity; beneath them rivers will flow; they will be adorned therein with bracelets of gold, and they will wear green garments of fine silk and heavy brocade: They will recline therein on raised thrones. How good the recompense! How beautiful a couch to recline on!

Pickthall: As for such, theirs will be Gardens of Eden, wherein rivers flow beneath them; therein they will be given armlets of gold and will wear green robes of finest silk and gold embroidery, reclining upon throne therein. Blest the reward, and fair the restingplace!

Muhammad Asad: theirs shall be gardens of perpetual bliss - [gardens] through which running waters flow - wherein they will be adorned with bracelets of gold and will wear green garments of silk and brocade, [and] wherein upon couches they will recline:" how excellent a recompense, and how goodly a place to rest!

In addition, although all vegetation is referred to as green, a special and rare term is used to refer to the luscious foliage of Paradise 'mudhammatan' (al-Rahman 55: 64). This word is not only a rare or archaic term used only once in the Ever-Glorious Quran, but it is also in the dual case (ending in- $a n$ ) and credited to be the shortest verse in the Quran:

$$
\text { قال تعالى: مُدْهَامََََانِ. }
$$


The word 'mudhammatan' comes from the Arabic word 'adham' which means "of very dark colour". One of the three interpretations under discussion has marked this dual case of the word in its interpretation into English. That is clear in Asad's 'two [gardens] of the deepest green'.

Muhammad Asad: Two [gardens] of the deepest green.

However, Pickthall and Ali did not denote this dual case of the word:

Pickthal: Dark green with foliage.

Yusuf Ali: Dark-green in colour (from plentiful watering).

In all of the three interpretations, the foreignisation strategy is adopted and the expressions 'dark green' or 'the deepest green' are used. Another example of a verse including the colour term 'green' is (al-Hajj 22:63):

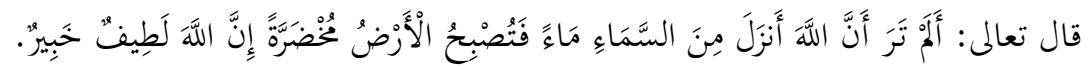

In the interpretation of the colour term green 'mukhdarrah', the foreignisation strategy was adopted in different ways. Pickthall and Asad adopted the foreignisation strategy when they interpreted it into 'becometh green' and 'becomes green':

Pickthall: Seest thou not how Allah sendeth down water from the sky and then the earth becometh green upon the morrow? Lo! Allah is Subtile, Aware.

Muhammad Asad: Art thou not aware that it's God who sends down water from the skies, whereupon the earth becomes green? Verily, God is unfathomable [in His wisdom], all-aware.

Yusuf Ali, as well, adopted the foreignisation strategy in the interpretation of the colour term into 'becomes clothed with green' in a metaphoric image to emphasize that the colour covered all the earth:

Yusuf Ali: Seest thou not that Allah sends down rain from the sky, and forthwith the earth becomes clothed with green? For Allah is He Who understands the finest mysteries and is well-acquainted (with them).

\section{Results and Discussion}

The above investigation shows that colour terms in the Ever-Glorious Quran are interpreted following a variety of strategies. Long debates have been held to discuss when to paraphrase and when to translate literally by adopting foreignisation. However, the above analysis has shown that foreignisation and paraphrase are both employed in interpreting colour terms in the Ever-Glorious Quran. It is clear from the above colour terms comparative analysis of three authentic interpretations of the Ever-Glorious Quran that foreignisation is the most successful strategy in this case. In the interpretation of the Ever-Glorious Quran, the source language is Arabic, when interpreting it; most interpreters foreignise the values of the Arabic language and impose them on the Target Language. When translators use Foreignisation, they keep the SL values and make them salient in the TL.

https://doi.org/10.24035/ijit.16.2019.001 
Whether to use paraphrase or foreignisation would always be under debate. As far as Arabic is concerned, native translators of Arabic would use domestication most of the time when they translate into Arabic and would use foreignisation when they translate from Arabic especially when they interpret the meanings of the Ever-Glorious Quran (al-Dammad 2008: 4). It is axiomatic from the interpretations analysed that most interpreters followed the foreignisation strategy in order to keep loyal to the message of the Ever-Glorious Quran and to commit to its language. In the above analysis, it is demonstrated that the most successful translation is the one that preserved the SL values. The paraphrase approach comes in the second rank as it was adopted in some interpretations especially that of Muhammad Asad.

To conclude, the difficulty of interpreting colour terms and colour-related idioms lies in the fact that they can be quite different across cultures and languages. This study has explored the interpretation of several colour terms in the Ever-Glorious Quran. It is a practical attempt to demonstrate that different modes of translation complement each other. "Paraphrase" is a powerful strategy in translating Arabic colour-related expressions that can be applied when no equivalent is found in the (TL) because of cultural divergences. Some of the foreignised interpretation choices of colour terms explored in the study were accompanied with explanations. In other words, if an expression does not have a replica in the (TL), or direct equivalents for idiomatic colour-expression are not available, paraphrasing would be sufficient and acceptable to the target audience.

\section{References}

Abu-Ssaydeh, A. 2004. Translation of English idioms into Arabic. <http://www.benjamins.com/cgibin/t_articles.cgi?bookid=Babel50 :2\& artid = 237052692> Retrieved: August 15, 2010.

al-Adaileh, B. 2012. The Connotations of Arabic Colour Terms. Linguistica Online. http://www.phil.muni.cz/linguistica/. Retrieved: April 15, 2019.

Asad, M. 1980. The Message of the Quran. Gibraltar: Dar al-Andalus.

Baker, M. 1992. In Other Words. London: Routledge.

Berlin, B. \& Kay, P. 1969. Basic Colour Terms: Their Universality and Evolution. Berkeley: University of California Press.

al-Bzour, S. 2015. Connotations of the straightforward colours in the Holy Quran: an analytical study. American Journal of Humanities and Social Sciences 3(4): 90-102.

al-Dammad, A. 2008. Domestication vs. Foreignisation in English-Arabic Translation. <htpp://www.proz.com/translation-articles/articles/1643/> Retrieved: January 11, 2011.

al-Domi, M. 2015. The connection between the colors mentioned in the Holy Quran and its significance the green model. European Scientific Journal 11(26): 167-178.

Metwally, A. 2019. Foreignising versus domesticating translations of Arabic colour-related expressions. Journal of Language Teaching and Research 10(2): 383-390.

Philip, G. 2006. Connotative meaning in English and Italian colour-word metaphors. Metaphorik 10:59-61. Pickthall, M. 1938. The Meaning of the Glorious Koran. Hyderabad: Government Central Press.

al-Qurtubi, A. 1964. Al-Jami' li Ahkam al-Qur'an wa al-Mubayin lima tadammana min al-Sunnah wa Ahkam al-Furqan [Interpretation of the Meanings of the Qur'ān]. 2nd ed. Cairo: Dar al-Kutub al-Misriyyah.

Ramiere, N. 2006. Reaching a Foreign Audience: Cultural Transfers in Audiovisual Translation. http://www .jostrans.or/ issue06/art_ramiere.pdf. Retrieved: August 20, 2010.

al-Shawi, M. 2014. Significance of colors in the Noble Quran and the ethics of translating them into English: an empirical study on some verses. Arab World English Journal 5(3): 65-76.

Venuti, L. 1995. The Translator's Invisibility: A History of Translation. London: Routledge.

Yusuf Ali, A. 1992. The Meaning of the Holy Qur'ān. 4th ed. Washington: Amana Corporation. 